\title{
Finite Element Analysis of External Gear Pump Based on ANSYS Workbench
}

\author{
Li Shuo $^{1}$, Xiao Shuhao ${ }^{1}$ \&Zhou Guoqiang ${ }^{2}$ \\ ${ }^{1}$ College of Mechanical\&electronical, Huazhong University of Science and Technology Wuchang \\ Branch \\ Wuhan, 430070, China \\ ${ }^{2}$ College of Mechanical\&electronical, Huazhong University of Science and Technology Wuchang \\ Branch \\ Wuhan, 430070, China
}

Keywords: Gear mesh; Finite element; The contact stress; Nonlinear.

\begin{abstract}
Gear pump with simple structure, high cost performance, reliable in performance is widely used in engineering machinery, agricultural machinery and so on.With the rapid development of modern science technology and industry, higher request are put forward to gear pump gear transmission. Therefore, the contacting strength problem of gear has become the focus of scholars at home and abroad and topics.

In the process of gear meshing, the contacting strength calculation of gear become a complex nonlinear contact problem due to the tooth surface elastic deformation and nonlinear contacting load distribution. And contact problem belongs to the variable boundary problem.It makes contact analysis to be an iterative process because of the uncertainty of the border issue. Therefore,the traditional calculation method not only greatly increase the difficulty of the analyzed operation, also reduced the accuracy of the result. So the finite element analysis method for calculating the gear contact stress provides a new method and means. and the deformation and stress in the calculated have high credibility.

In this paper, Based on gear engagement principle, the gear contact analysis and finite element analysis method, this paper introduced the use of static structural analysis modules in the ANSYS workbench.And there is an non-linear contact analysis of involute cylindrical gear meshing model through it.the gear is obtained under normal working stress deformation and stress. Comparing with the actual working condition, it is concluded that the direction of the gear can be optimized.
\end{abstract}

\section{Introduction}

Based on CNN-E300 series gear pump as the research object, this series of pump is suitable for low pressure hydraulic system, used to transport oil temperature at $10{ }^{\circ} \mathrm{C} \sim 60{ }^{\circ} \mathrm{C}$, rotating speed of 1000-1500 revolutions per minute, used in hydraulic machinery, machine tools, engineering machinery hydraulic system, can also be used to dilute gas station, oil, chemical industry, metallurgy, mining, textile machinery and other equipment as the power source of the system. The rated pressure is $16 \mathrm{MPa}$, maximum pressure is $20 \mathrm{MPa}$, rated speed is $2000 \mathrm{r} / \mathrm{min}$.

Model design.Because the gear suction and pressure oil is done by meshing, two gear structure has the same parameters. To simplify the analysis, we selected the same tooth face for the two gears, the gear basic parameters such as shown in table 1 .

Table 1 The gear basic parameters

\begin{tabular}{c|c|c|c|c|c}
\hline Gear & $\begin{array}{c}\text { The } \\
\text { modulus } \\
(\mathrm{mm})\end{array}$ & $\begin{array}{c}\text { Number } \\
\text { of teeth }\end{array}$ & $\begin{array}{c}\text { The addendum } \\
\text { circle diameter } \\
(\mathrm{mm})\end{array}$ & $\begin{array}{c}\text { Tooth root } \\
\text { circle diameter } \\
(\mathrm{mm})\end{array}$ & $\begin{array}{c}\text { Pressure } \\
\text { Angle }\left(^{\circ}\right)\end{array}$ \\
\hline driving wheel & 3 & 10 & 30 & 22.5 & 20 \\
\hline driven wheel & 3 & 10 & 30 & 22.5 & 20 \\
\hline
\end{tabular}

Entity model was made by mainly UG8.0 modeling software, the model was shown in figure1. 


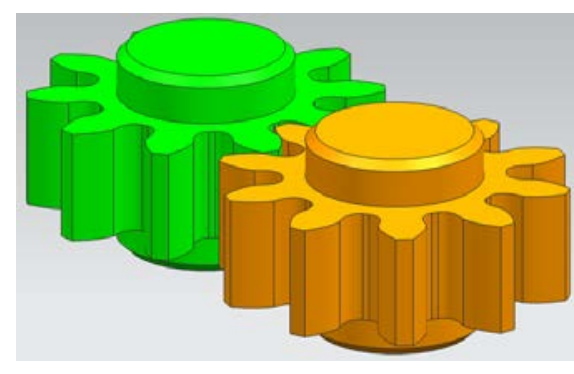

Figure1 The geometric model of the gear

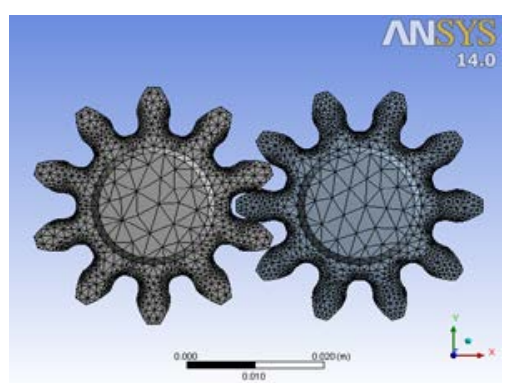

Figure2 meshing figure

The establishment of the finite element model.Gear materials are high strength aluminum alloy 6061-T651, its main parameters and mechanical properties as shown in table 2.

Table2 Material and main physical parameters and mechanical properties

\begin{tabular}{c|c|c|c|c}
\hline Material & $\begin{array}{c}\text { Modulus of } \\
\text { elasticity E/GPa }\end{array}$ & $\begin{array}{c}\text { Poisson's } \\
\text { ratio } \mu\end{array}$ & $\begin{array}{c}\text { Ultimate } \\
\text { strength } \\
\sigma \mathrm{b} / \mathrm{MPa}\end{array}$ & $\begin{array}{c}\text { Density / kg/m } \\
3\end{array}$ \\
\hline 6061-T651 & 68.9 & 0.33 & 386 & 2730 \\
\hline
\end{tabular}

Contact problem is a highly nonlinear problem, it belongs to the variable boundary problem, both because of the friction area size change and nonlinear and produce nonlinear, due to the contact pressure distribution changing and non-linear and friction effect. Because of uncertainty boundary surface and nonlinear contact problem solving, it become an iterative process.

In the finite element displacement method, to ensure the coordination of internal continuity and across units, the displacement mode shape function can be properly choosen without having to add other conditions. But in the contact problem, we should consider contact connection, which in addition to ensure that contact with internal body deformation coordination, still ensure all the contact body along the boundary of the contact deformation coordination. In this paper, we choose the static structural analys because assumed unit rotation and deformation is very small,. There are five types in ANSYS Workbench mechanical contact type. Here we choose friction (frictional), and set the friction coefficient of 0.16 . To avoid penetrating target surface, the contact can be selected symmetric contact behavior. Add motion pair, change the connection type to the body - ground, change the type to revolute, selected axis of gear 1 round surface, and set to it rigid behaviors, set the movement of gear 2 pair with the same method.

Meshing quality has a direct impact on the accuracy of analysis, therefore,we must choose accurate classification method. The small cell division, the higher the calculation precision, but solving time significantly increased. Therefore, in the gear mesh, in order to get accurate contact stress and keep the quality of the whole grid, overall preliminary classification was carried out on the gear firstly, refinement was done in where stress gradient is larger in acute stress changes, thinning of tooth root and tooth surface contact area.

In order to get the good quality grid, set to medium in smoothing, set as fast in the transition, the span Angle center set to fine, the initial size of seed set to active the assembly, the mesh in the metric as skewness, in high dimension function use the advanced size function is set to "On, proximity and curvature”.

The good grid as shown in figure 3, where the gear axis and away from the contact surface, meshing is relatively loose, the contact point is more close, this is not only reasonable to save time, also ensure the quality of the grid and ensure the accuracy of analysis results.

\section{The finite element static analysis}

Stress analysis and boundary conditions.Because of the material density is small, ignore the influence of weight. As a result of the movement of the gear for the periodic motion, need to set a time step, the step end time is set to 5s. Gear in the process of movement, mainly by the contact stress of the meshing, therefore this article applied cyclic load and cyclic torque of gear with 
$50 \mathrm{~N} \cdot \mathrm{mm}$ (ramped), set up two gears rotate in opposite directions. Selected the main shaft of a gear circle surface as constraints.

The results of the analysis.It was shown in Fig3, gear transmission of tensile stress,compressive stress and small deformation is very small in the process of gear meshing. The strain is in the process of the mesh in the elastic deformation stage, at the same time from several other pictures, it can be obtained step jump is also relatively slow in the gear mesh alternating. The reason mainly has the following two points:

(1)Set for the rigid contact surface contact, not fully consider the effect of deformation on the stress changes;

(2)Ignore the influence of the external environment, without considering the hydraulic oil thermal environment on the influence of elastic modulus and deformation and ignore the influence of gear its weight.

Eventually even considering these two factors, it has a little influence on stress and strain of gear. From the perspective of safe use and life expectancy, the use of gear completely reached the requirement. But from the economical point of view, this is not conducive to reducing costs, so structure optimization should be done in order to reduce the manufacturing cost.
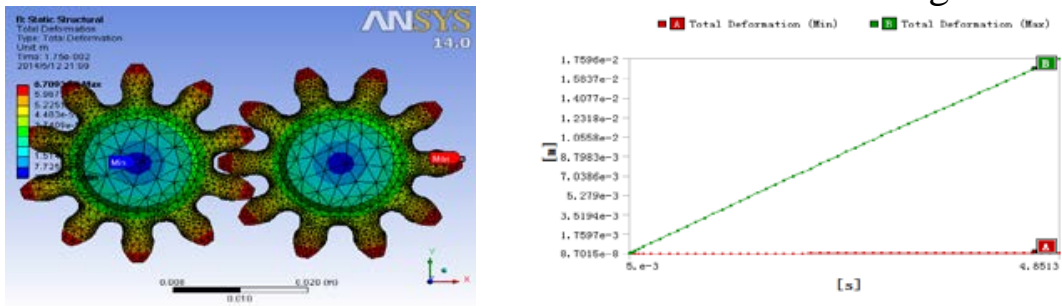

Figure 3 The total deformation and deformation curve
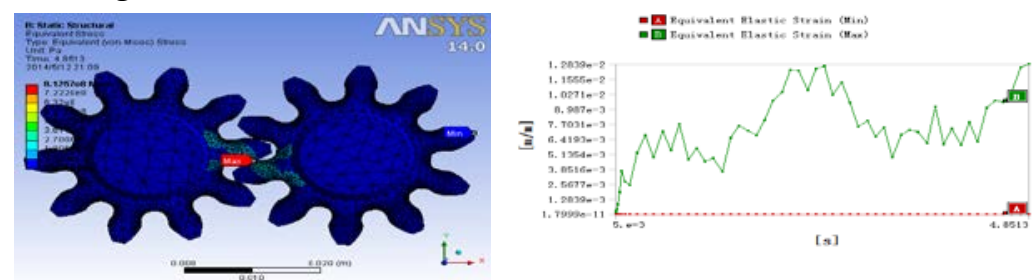

Figure4 Average pressure and curve
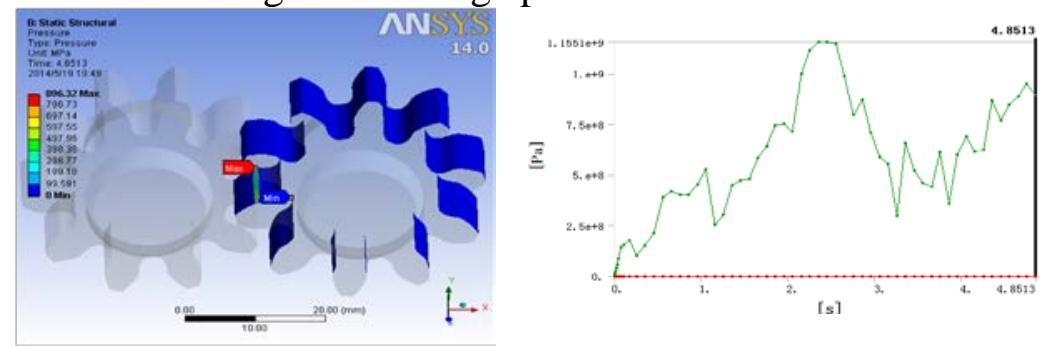

Figure5 Contact pressure and the curve

\section{Optimal design of gear}

Gear data such as size and material parameters should be optimized firstly, so gear was modeled with Solidworks modeling software again.Therefore, in the gear optimization, the material was changed and the gear was dig into hole. Specific Settings is as follows: the axial dig a hole is 10 $\mathrm{mm}$ in diameter, material change to 5803 - H112, material properties, such as table 3.

Table 3 5803-H112 The performance parameters

\begin{tabular}{c|c|c|c|c}
\hline Density & The tensile strength & The yield strength & Poisson's ratio & elongation \\
\hline $2.72 \mathrm{~g} / \mathrm{cm}^{3}$ & $180 \mathrm{MPa}$ & $211 \mathrm{MPa}$ & 0.33 & 14 \\
\hline
\end{tabular}


Analysis and solution of the optimized.Meshing of gear after optimization is shown in figure 6, the solution of average pressure as shown in figure 7.

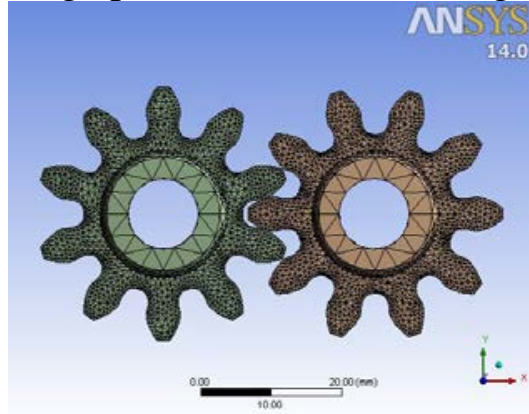

Figure 6 Gear meshes

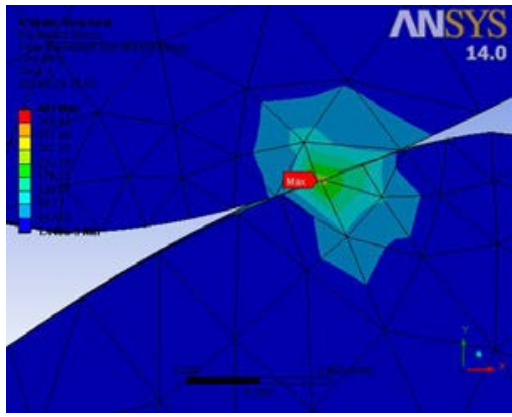

Figure7 Average pressure figure

Contact analysis from above, the stress of the gear is in the yield limit, and the whole tooth surface stress becomes uniform after the material properties and gear structure changed, it shows that the optimization direction of gear is desirable, and the optimization of gear, can save the manufacturing cost, also can increase the bearing capacity, thus improve the rated pressure.

Through the above analysis, we can get: the optimization direction has feasibility, it can meet the normal working conditions, reduce the manufacturing cost, and improve work pressure rated in certain circumstances, to meet the requirements of the industry of high pressure gear pump.through the optimization of gear.

\section{Conclusions}

This paper studied the problems of the external gear pump gear contact finite element analysis, The method is simple by using the ANSYS Workbench, and avoid the traditional tedious calculation method, reduce the computational complexity. Using ANSYS as a tool for stress analysis, using the Workbench of tooth model import, loads and constraints, applying, etc. Series of finite element analysis, obtained the stress distribution and deformation of the gear contours; Through finite element analysis, obtained the work situation of gear, gear can be analyzed and the rationality of structure design and material selection, on the basis of optimized design, satisfy the requirement of work and life in the circumstances, to reduce the manufacturing cost.Through the analysis of gear assumptions and optimization, get the gear feasible optimization direction.

\section{References}

[1] Xu Hao. Mechanical Design Handbook (I). Beijing: Mechanical Industry Press, 2000.6

[2] Xu Hao. Mechanical Design Handbook (II). Beijing: Mechanical Industry Press, 2000.6

[3] Awaludin.A.,Hirai,T.A finite element analysis of bearing resistance of timber loaded through a steel plate,2012(11):1-6

[4] Francois H. Burger, Jaco Dirker, Josua P. Meyer. Three-dimensional conductive heat transfer topology optimisation in a cubic domain for the volume-to-surface problem [J]. International Journal of Heat and Mass Transfer, 2013, 67: 214-224.

[5] Li Bing. ANSYS Workbench design, simulation and optimization.Beijing:qsinghuaUniversity Press,2013.

[6] Ling Guilong,Ding Jinbin,Zou Zheng.ANSYS Workbench13.0 from entry to the master. Beijing: Qsinghua University Press,2012. 